\title{
Galen Vein Thrombosis With Bilateral Thalamus Infarction
}

\author{
Hosein Delavar Kasmaei ${ }^{1}$; Alireza Baratloo ${ }^{2}$; Amir Saeed Seddighi ${ }^{3}$; Fatemeh Shabani ${ }^{1,}$; \\ Mohammad Tafreshian ${ }^{1}$ \\ ${ }_{1}^{1}$ Department of Neurology, Shohadaye Tajrish Hospital, Shahid Beheshti University of Medical Sciences, Tehran, IR Iran \\ 2 Department of Emergency Medicine, Shohadaye Tajrish Hospital, Shahid Beheshti University of Medical Sciences, Tehran, IR Iran \\ 3 Department of Neurosurgery, Shohadaye Tajrish Hospital, Shahid Beheshti University of Medical Sciences, Tehran, IR Iran \\ ${ }^{*}$ Corresponding author: Fatemeh Shabani, Department of Neurology, Shohadaye Tajrish Hospital, Shahid Beheshti University of Medical Sciences, Tehran, IR Iran. Tel:+98-9121579198, \\ Fax:+98-2122721155, E-mail: dr.fatemeshabani@gmail.com
}

Received: March 19, 2014; Revised: September 3, 2014; Accepted: October 1, 2014

\begin{abstract}
Introduction: Deep venous thrombosis presents with different clinical symptoms and signs, which can be diagnosed incorrectly. Bilateral thalamus infarction is one of the rare manifestations which can be misinterpreted as a different diagnosis and lead to mismanagement. Case Presentation: We reported a 37-year-old female referred to the emergency department with headache, left side weakness, seizure and alteration of consciousness at the admission time. She had been misdiagnosed with brain tumor because of her imaging results at first. However, in the follow up, she was diagnosed with deep cerebral venous thrombosis of the vein of Galen based on the brain magnetic resonance imaging(MRI) result. Afterwards, she was treated by anticoagulant (heparin) and recovered well.

Conclusions: This case was presented to emphasize the importance of different manifestations of deep vein thrombosis which can lead to delayed appropriate treatment due to misdiagnosis.
\end{abstract}

Keywords:Galen Vein; Cerebral Vein; Thrombosis; Thalamus; Infarction

\section{Introduction}

Cerebral deep venous thrombosis (CDVT) of Galen vein is an uncommon disorder manifested by bilateral thalamic infarcts, which can lead to poor outcomes without proper treatment. CDVT is a vascular disease with many clinical manifestations which makes the diagnosis difficult $(1,2)$. In this study, a case of Galen vein thrombosis with bi-thalami infarction was presented.

\section{Case Presentation}

A 37-year-old female was admitted to the emergency department following tonic-colonic seizures occurring twice. She had had headache with acute onset since 11 days before coming to the hospital. Her headache was generalized and continuous all the time. She also had nausea and vomiting. Two days after the unset of her headache, mild weakness of her left limbs occurred. Her seizures occurred nine days later, which repeated twice a day, while she did not have any history of seizures before. Because of her ovarian cyst, she was consuming oral contraceptive pill (OCP) since 2-3 months before. She was confused and drowsy at the admission time. She did not have fever and neck rigidity. She had a mild right facial paresis, but examination results of other cranial nerves were normal. The tone and force of left limbs had decreased and it was 4 upon 5. Plantar reflex in the left side was up, but in the right side it was down. At first, she was admit- ted in the neurosurgery department with the diagnosis of diencephalon tumor because of her imaging result as well as the stereotaxic biopsy of the lesion. However, the diagnosis of CDVT was finally confirmed by reviewing the imaging results (Figure 1 and 2 ).

After that, treatments with anticoagulant (heparin) and then warfarin were performed. In addition, she was treated by an anticonvulsive drug (phenytoin). She had a good recovery through this treatment; her headache and neurological deficits were eliminated and she became quite oriented.

\section{Discussion}

CDVT is a rare variety of cerebral vein and sinus thrombosis, especially in OCP users, so that clinical information regarding its presentation, course and outcome are limited. Due to variable clinical presentations of CDVT, its diagnosis is often difficult; therefore, heparin treatment has been established with substantial delay, which is generally accompanied with poor prognosis $(3,4)$. Occlusion of the Galen vein and internal cerebral veins is the least common and most clinically obscurities of venous syndromes. From the few studied cases, a picture of bi-thalamic infarction emerged, which was sometimes reversible, mainly consisting inattention, spatial neglect, amnesia and akinetic mutism, as well as apathy. Other cases manifested coma and pupillary changes, referable to ischemic diencephalon and rostral midbrain.

Copyright (C) 2015, Tehran University of Medical Sciences. This is an open-access article distributed under the terms of the Creative Commons Attribution-NonCommercial 4.0 International License (http://creativecommons.org/licenses/by-nc/4.0/) which permits copy and redistribute the material just in noncommercial usages, provided the original work is properly cited. 

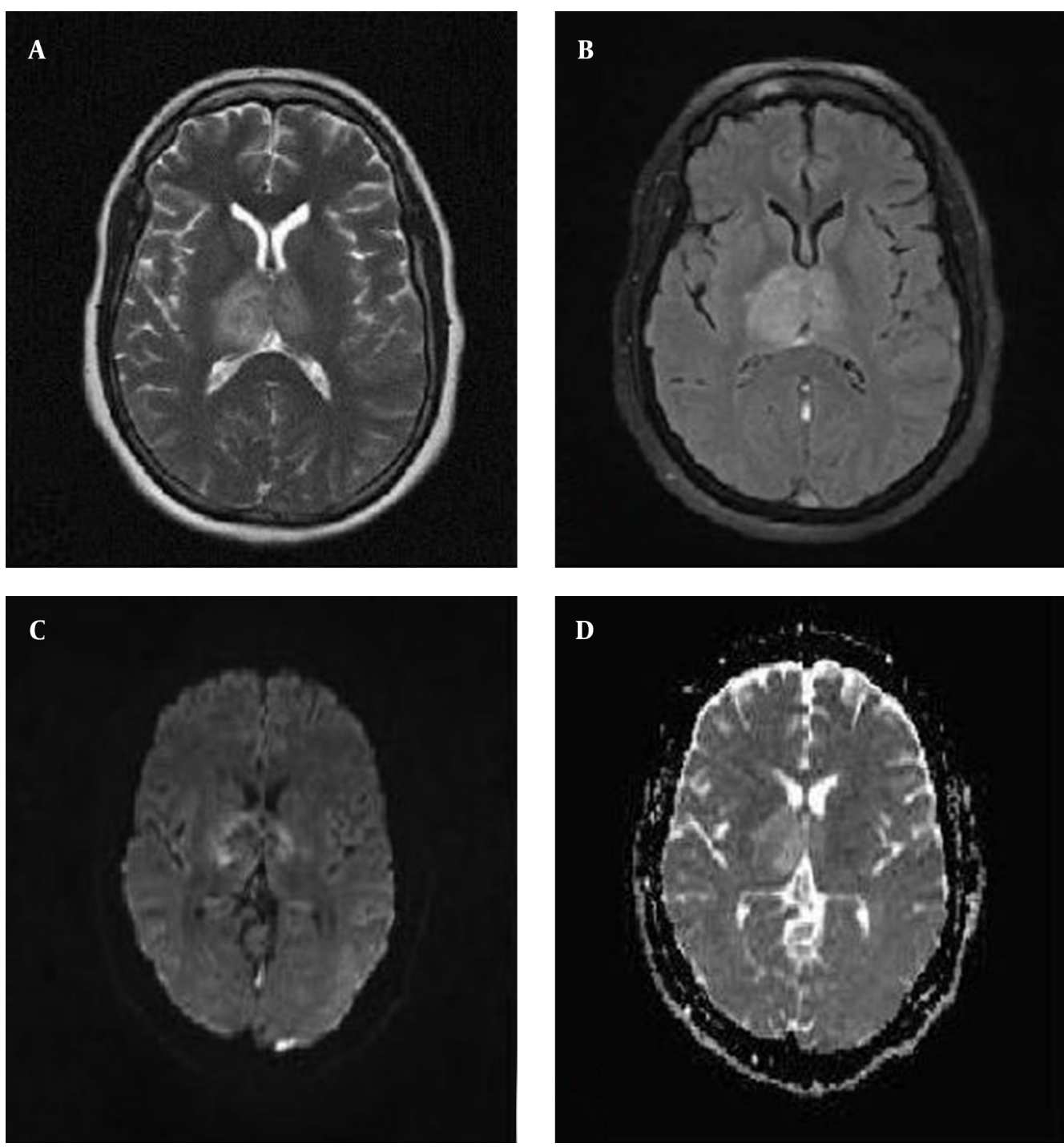

Figure 1. Brain Magnetic Resonance Imaging Without Gadolinium Showing Lesion in Both Thalami in T2 (A), FLAIR (B), DW (C) and ADC (D) Views
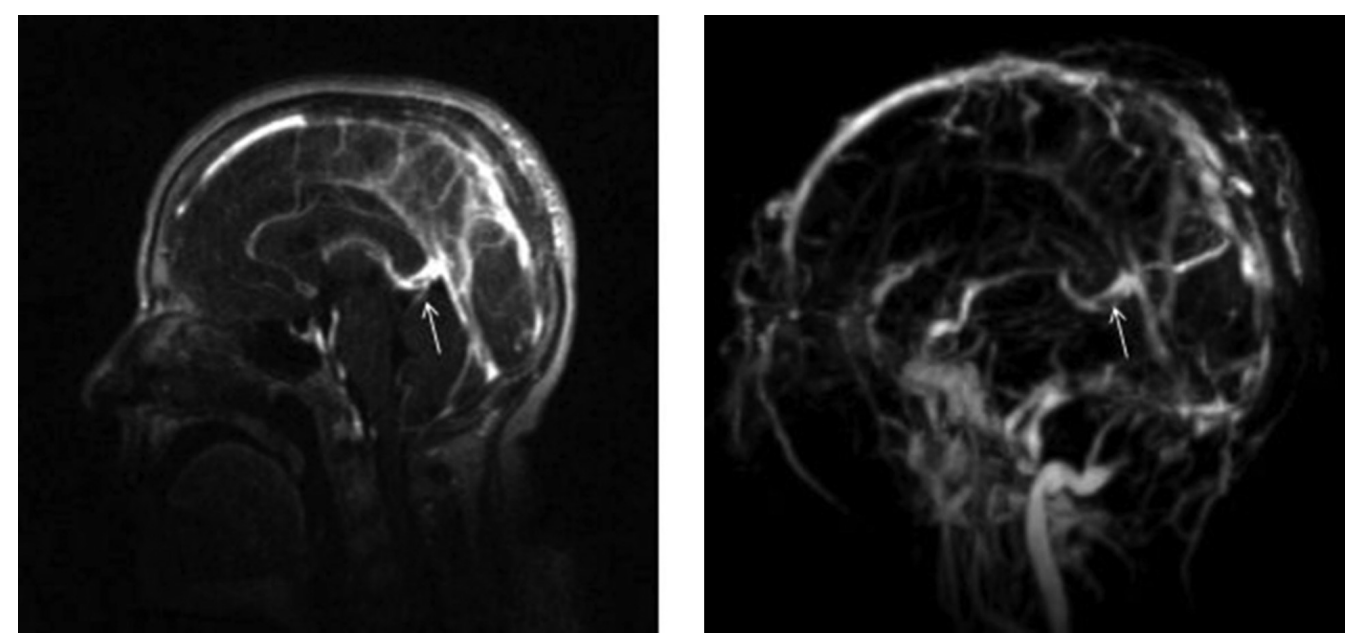

Figure 2. Brain Magnetic Resonance Venography Showing Filling Defect in the Galen Vein 
Therefore, clinical demonstrations of CDVT can be nonspecific and can cover the changes in mental status, alter consciousness, and even lead to coma $(5,6)$.

Thrombosis of Galen vein is a rather fatal event, resulting in venous hypertension, infarction, and hemorrhage, than a slow and easy-going clinical course. Patients get referred to a neurologist after interventions and different care modalities. Even though partial flow disturbance in the course of Galen vein has somehow contributed to the course of the disease, perhaps, it has not been the main causative element (7-9). Changes shown by the white arrows in the magnetic resonance venography (MRV) (Figure 2) could also be due to a stenosis, duplication, or fenestration rather than thrombus formation; but, response to the treatment highlighted the possibility of thrombosis. Imaging-based diagnosis of CDVT is usually problematic due to the absence of characteristic delta sign of superior sagittal sinus thrombosis on contrast enhanced CT scan. Furthermore, normal variability of flow-related signals in straight sinus on MRI leads to seduction. However, deep veins hyperdense thrombus on CT scan can be suggestive for the diagnosis and MRI and MRV can serve as confirmatory tools, by showing hyperintense lesion on T2-weighted and hypointense ones on T1-weighted images that related to ischemia and vasogenic edema, induced by CDVT (10-13). The intraluminal clot clearly appeared as an area of hyperintensity on $\mathrm{T} 1$ weighted images and the absence of flow signal in MRV (14). Heparin has been accepted as the cornerstone of treatment in primary encounter and invasive procedures such as endovascular thrombolysis; in more severe cases, decompressive hemicraniectomy is left for nonresponsive cases. Accompanied neurological complications such as seizures and intracranial hypertension require specific treatments $(12,15)$.

CDVT with numerous clinical features is usually associated with diagnostic difficulty. We described a case of Galen vein thrombosis to emphasize the importance of different manifestations of deep vein thrombosis which can lead to delay in appropriate treatment due to misdiagnosis.

\section{Acknowledgements}

We would like to thank all the emergency and neurology department staff who helped in diagnosis and management of this patient.

\section{Authors' contributions}

Study supervision and case management: Hosein Delavar Kasmaei and Amir Saeed Seddighi. Study concept and design; critical revision of the manuscript for important intellectual content: Alireza Baratloo. Acquisition of data: Mohammad Tafreshian. Drafting of the manuscript and corresponding: Fatemeh Shabani.

\section{Funding/Support}

All authors declared that this study was accomplished without any funding or support and the authors were responsible for all the expense.

\section{Role of the sponsor}

All the authors declared that this study was conducted without the help of any sponsor.

\section{References}

1. Kasmaei HD, Baratloo A, Soleymani M. A 33-year-old woman with severe postpartum headache. Emergency. 2013;1(1):pp. 27-9.

2. Wieshmann NH, Amin S, Hodgson R. A case of unilateral thalamic hemorrhagic infarction as a result of the vein of Galen and straight sinus thrombosis. J Stroke Cerebrovasc Dis. 2009;18(1):2831.

3. Pfefferkorn T, Crassard I, Linn J, Dichgans M, Boukobza M, Bousser MG. Clinical features, course and outcome in deep cerebral venous system thrombosis: an analysis of 32 cases. J Neurol. 2009;256(11):1839-45.

4. Baratloo A, Safari S, Rouhipour A, Hashemi B, Rahmati F, Motamedi M, et al. The Risk of Venous Thromboembolism with Different Generation of Oral Contraceptives; a Systematic Review and Meta-Analysis. Emergency. 2014;2(1):1-11.

5. Ropper A, Samuels M. Adams and Victor's Principles of Neurology. 9 ed: Mcgraw-hill; 2009.

6. Lacour JC, Ducrocq X, Anxionnat R, Taillandier L, Auque J, Weber M. [Thrombosis of deep cerebral veins in form adults: clinical features and diagnostic approach]. Rev neurolo. 2000;156(10):851-7.

7. Latchaw RE, Yonas H, Hunter GJ, Yuh WT, Ueda T, Sorensen AG, et al. Guidelines and recommendations for perfusion imaging in cerebral ischemia: A scientific statement for healthcare professionals by the writing group on perfusion imaging, from the Council on Cardiovascular Radiology of the American Heart Association. Stroke. 2003;34(4):1084-104.

8. Mortazavi MM, Griessenauer CJ, Foreman P, Bavarsad Shahripour R, Shoja MM, Rozzelle CJ, et al. Vein of Galen aneurysmal malformations: critical analysis of the literature with proposal of a new classification system. J Neurosurg Pediatr. 2013;12(3):293-306.

9. Sasaki T, Kurita H, Saito I, Kawamoto S, Nemoto S, Terahara A et al. Arteriovenous malformations in the basal ganglia and thalamus: management and results in 101 cases. J Neurosurg. 1998;88(2):285-92.

10. Kamal AK, Itrat A, Shoukat S, Khealani A, Kamal K. Isolated deep venous thrombosis-case series, literature review and long term follow up.J Pak Med Assoc. 2006;56(11):557-9.

11. Arhami Dolatabadi A, Baratloo A, Rouhipour A, Abdalvand A Hatamabadi $\mathrm{H}$, Forouzanfar M, et al. Interpretation of Computed Tomography of the Head: Emergency Physicians versus Radiologists. Trauma Mon. 2013;18(2):86-9.

12. Sagduyu A, Sirin H, Mulayim S, Bademkiran F, Yunten N, Kitis $\mathrm{O}$, et al. Cerebral cortical and deep venous thrombosis without sinus thrombosis: clinical MRI correlates. Acta Neurol Scand. 2006;114(4):254-60.

13. Herrmann KA, Sporer B, Yousry TA. Thrombosis of the internal cerebral vein associated with transient unilateral thalamic edema: a case report and review of the literature. AJNR Am J Neuroradiol. 2004;25(8):1351-5.

14. Honda M, Kaminogo M, Nagata I, Morikawa M. [Deep cerebral venous thrombosis: a report of three cases and review of the literature]. No To Shinkei.2004;56(8):689-94.

15. Coutinho JM, Stam J. How to treat cerebral venous and sinus thrombosis. J Thromb Haemost. 2010;8(5):877-83. 